\title{
Feinblasig klingend
}

\author{
B. Gurtner
}

Als Statussymbol wird das Stethoskop den Stirnspiegel verdrängen, den die Karikaturisten zur Kennzeichnung der Mediziner so gerne verwendet haben. Der supranasale Scheinwerfer dient ohnehin nur noch einigen Spezialisten als Grubenlampe. Moderne Ärzte tragen ihr flexibles Abhörgerät lässig um den Hals geschlungen, um so augenfälliger, je weniger sie damit umzugehen wissen.

Die Auskultation hat für heutige Medizinstudentinnen und ihre in die Minderheit versetzten Kommilitonen kaum mehr den Stellenwert wie zur Zeit der klassischen «Pöpperlikurse». Vorboten dieser Entwicklung waren jene Unterassistenten, welche teure Littman-Stethoskope mit ins Praktikum brachten, jedoch nicht wussten, wozu der Edelstahltrichter und wofür die Membran am drehbaren Schallkopf zu gebrauchen sind. Sogar die Kardiologen verlernen allmählich die Feindiagnostik, welche ihre klinischen Lehrer bei der nicht apparativen Untersuchung ihrer Herzpatienten beherrscht hatten. Die Echokardiographie liefert objektivere Befunde als ein je nach Ohrenschmalz zu 4/6 oder schwächer wahrgenommenes spätdiastolisches Gemurmel, Austin-Flint und Graham-Steell gehören nicht mehr zum Prüfungsstoff im Staatsexamen.

Laut Überlieferung soll es René Théophile Hyacinthe Laennec (1781-1826) als unziemlich empfunden haben, sein Ohr einer abzuhorchenden Dame direkt auf die entblösste Brust zu legen. Er rollte sein Notizheft zu einem Zylinder et voilà - das Stethoskop für die «auscultation médiate» war erfunden. Die ersten aus Holz gedrechselten Modelle hatten die Form eines langstieligen Sektglases. Sie glichen den robusten Geräten, die Hebammen den Schwangeren auf die Bauchdecke pressen, wenn sie fetale Herztöne suchen und dabei selbst in Querlage geraten.

Laennec hat 1819 seine Hörbefunde in einem zweibändigen Lehrbuch dokumentiert und interpretiert. Er selbst starb nur 45jährig an einer Lungentuberkulose, die er sich als Berufskrankheit zugezogen hatte. Mangels besserer diagnostischer Hilfsmittel entwickelte sich die Auskultation im 19. Jahrhundert zur hohen Kunst. Wie der Gesang seltener Vögel den Ornithologen erfreut, so fasziniert es Kliniker und Praktiker aber noch heute, wenn sie allein durch genaues Hin- hören einen Befund erheben können. Es entzücken sie Pleurageräusche, die an den knarrenden Velosattel oder an sich ablösende Klebestreifen erinnern. Geschulte Ohren erfassen frühzeitig ein diskretes Perikardreiben nach Herzinfarkt, den Hauch einer Klappeninsuffizienz oder den Trab eines frischen Galopprhythmusses. Sie werden reflexartig durch die hämmernden Bässe eines voll aufgedrehten Autoradios irritiert, weil sie das dumpfe Klopfen im vorbeifahrenden Sportwagen als bedrohliche Kammertachykardie empfinden. Sie hören es sofort, wenn einer Filmszene beschleunigte Herztöne unterlegt werden, um die Spannung zu erhöhen. Déformation professionnelle?!

Atemgeräusche kann man sprachlich nie befriedigend umschreiben. Auch deren Aufzeichnung in der KG wirkt kindlich unbeholfen, brav werden kleine Kreise ausgemalt und die Symbole für Giemen und Knacken im Untergeschoss verteilt. «Mittel- bis grobblasig klingende Rasselgeräusche» bezeichnen eher den Sound einer Guggenmusik als die «ohrnahen» Schallphänomene in einem kranken Respirationstrakt. Was muss man sich unter «nicht klingenden» Geräuschen vorstellen? Kommt hinzu, dass der orgelnde Bronchialbaum nach jedem Husten oder tiefen Durchatmen wieder andere Register zieht. Auf den Visiten hören die sukzessiv zur Auskultation gelangenden Teilnehmer allerlei Variationen zum Thema oder schliesslich gar nichts mehr. Die Netten an den Betten setzen ihre akustischen Saugnäpfe aber erst auf, nachdem sie die Schallköpfe in der Hand etwas vorgewärmt haben, sonst wird es für die Patienten schauderhaft.

Erfahrene Ärztinnen und Ärzte nehmen Blutdruckmessungen - zumindest beim ersten Mal immer selber vor, weil sie dabei die Verspanntheit oder vegetative Labilität der Untersuchten unmittelbar erfahren. Wenn Patienten zu sprechen beginnen, nachdem wir uns schon beide Oliven des Stethoskops in die Gehörgänge gestopft haben, realisieren sie nicht, wie andächtig die Korotkoff'schen Töne erlauscht werden müssen. Manchmal lohnt es sich aber doch, ein Ohr nochmals frei zu machen, um die wichtige Mitteilung oder Frage zu hören, die der Kranke sonst verschwiegen oder bis zur Verabschiedung unter Tür und Angel aufgespart hätte. Das wäre dann eine «auscultation immédiate». 